\title{
The effect of opioids on gastrointestinal function in the ICU
}

\author{
Yun Yan ${ }^{1,2} \mathbb{B}$, Yu Chen ${ }^{1,2^{*}}$ and Xijing Zhang ${ }^{1,2^{*}}$
}

\begin{abstract}
Gastrointestinal (Gl) dysfunction is common in the critical care setting and is highly associated with clinical outcomes. Opioids increase the risk for $\mathrm{Gl}$ dysfunction and are frequently prescribed to reduce pain in critically ill patients. However, the role of opioids in GI function remains uncertain in the ICU. This review aims to describe the effect of opioids on $\mathrm{Gl}$ motility, their potential risk of increasing infection and the treatment of $\mathrm{Gl}$ dysmotility with opioid antagonists in the ICU setting.
\end{abstract}

Keywords: Opioids, Critical illness, Gastrointestinal function, Gastrointestinal microbiome

\section{Introduction}

A round-table conference in 1997 concluded that GI function was crucial for the clinical outcomes of ICU patients and was associated with poor prognosis [1]. However, there is no unanimity about the definition of GI dysfunction [2-4]. The Working Group on Abdominal Problems (WGAP) recommended the term "acute gastrointestinal injury" (AGI) with four grades of severity be used to describe the GI function of critically ill patients [5]. AGI severity grades are better associated with clinical outcomes in critically ill patients and predict prognosis $[6,7]$. GI problems are common and occur in $50-60 \%$ of ICU patients [8]. A total of $59.1 \%$ of patients had at least one GI symptom during their first ICU stay, and $36.2 \%$ had two or more symptoms [9]. GI dysfunction includes high gastric residuals, gastroesophageal reflux, aspiration, constipation, diarrhoea, and abdominal distention and is associated with a prolonged length of stay in the ICU and increased mortality [10-13]. In this review, we provide an update on the impact of opioids on gastrointestinal function.

*Correspondence: chenyu007@gmail.com; zhangxj918@163.com

${ }^{1}$ Department of Anaesthesiology and Perioperative Medicine, Xijing Hospital, The Fourth Military Medical University, Xi'an, China

Full list of author information is available at the end of the article
Pain is ubiquitous in the ICU, with $50 \%$ of ICU patients suffering from moderate to severe pain [14]. Pain in the ICU has multiple aetiologies, including underlying illness, invasive therapy, incisions, daily care, penetrating catheters and tubes [15]. Furthermore, delirium, impaired communication, sleep deprivation and preexisting chronic pain exacerbate the pain experienced in the ICU [15]. Opioids are the cornerstone treatment for moderate to severe pain. Opioid prescriptions have quickly skyrocketed, and they are commonly administered in the ICU, with $63-86 \%$ of ICU patients treated with opioids $[16,17]$. However, the adverse effects of opioid therapy cause discomfort, seriously impact the patient's quality of life and can even lead to the discontinuation of treatment. Studies have shown that opioids strongly inhibit the GI tract [18-21]. The GI tract is sensitive to low doses of opioids, and an animal study demonstrated that onequarter of the morphine needed to produce analgesia inhibits intestinal motility and that one-twentieth of the analgesic dose is enough to treat diarrhoea [22].

\section{Distribution and physiological function of opioid receptors in the GI tract \\ Opioid receptors are widely distributed in the enteric nervous system (ENS) of the GI tract (Fig. 1). The primary opioid receptors include the mu opioid receptor (MOR), delta opioid receptor (DOR) and kappa opioid receptor} original author(s) and the source, provide a link to the Creative Commons licence, and indicate if changes were made. The images or other third party material in this article are included in the article's Creative Commons licence, unless indicated otherwise in a credit line to the material. If material is not included in the article's Creative Commons licence and your intended use is not permitted by statutory regulation or exceeds the permitted use, you will need to obtain permission directly from the copyright holder. To view a copy of this licence, visit http://creativecommons.org/licenses/by/4.0/. The Creative Commons Public Domain Dedication waiver (http://creativeco mmons.org/publicdomain/zero/1.0/) applies to the data made available in this article, unless otherwise stated in a credit line to the data. 


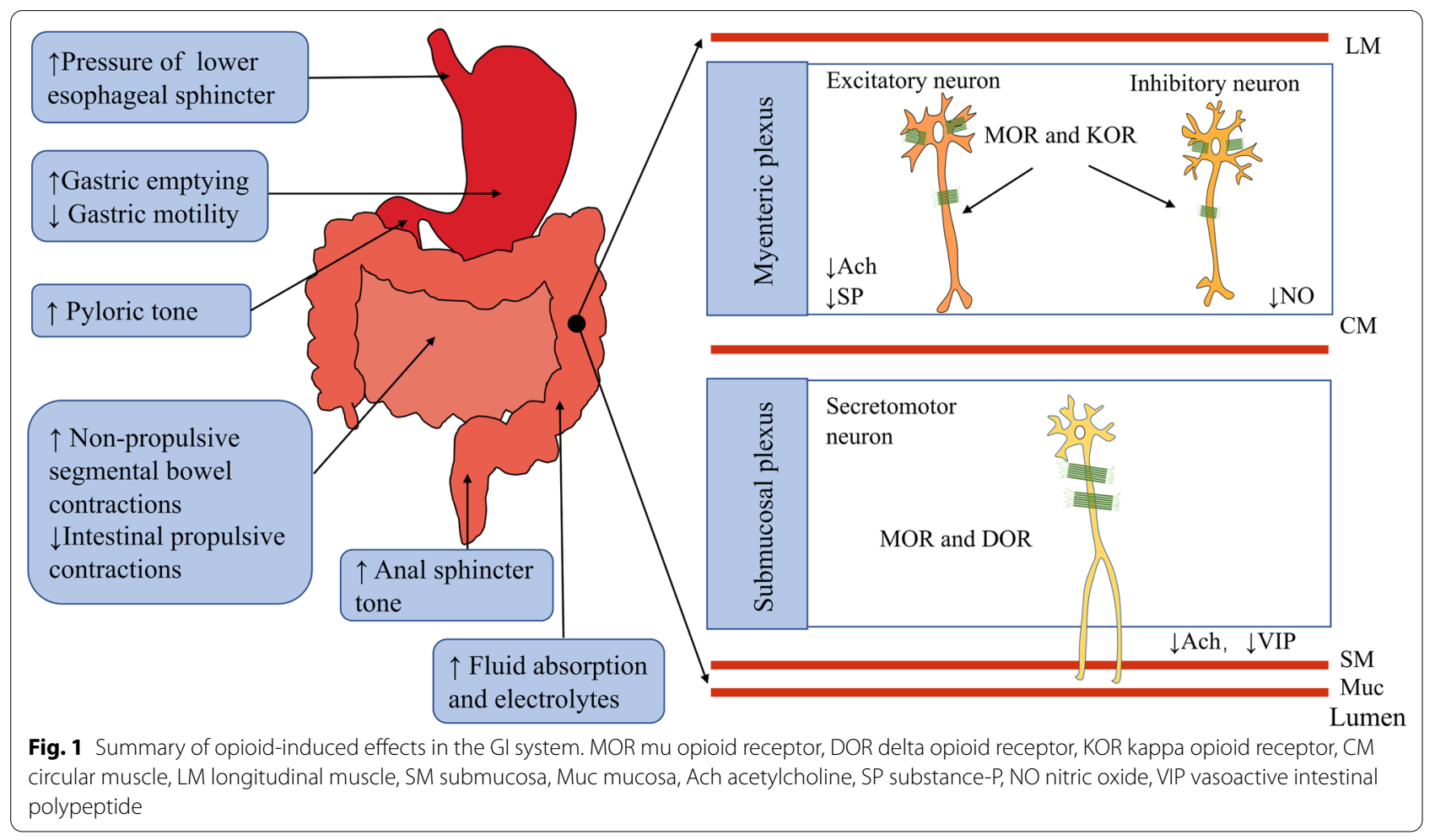

(KOR). Opioid receptors located in the interneurons, secretomotor neurons and musculomotor neurons of the ENS mainly sustain the homeostasis of the GI tract [23]. Inhibition of neuronal excitability and imbalance of neurotransmitter release are the principal mechanisms by which opioids regulate the GI tract [24]. The activation of opioid receptors can change the concentration of $\mathrm{K}^{+}$ and $\mathrm{Ca}^{2+}$ by $\mathrm{G}$ protein-coupled receptors and then lead to the suppression of neuronal depolarization, decreased neuronal excitability and the inhibition of neurotransmitter release (Fig. 2) [25]. Circular muscle and longitudinal muscle in the GI tract have different nerve inputs, and opioid receptor agonists impair the normal motility of the GI tract by increasing the contraction activities of circular muscle and decreasing the contraction activities of longitudinal muscle through the suppression of neuronal excitability [26]. The inhibition of the excitatory neurotransmitters acetylcholine and substance-P participate in the discoordination motility of the GI tract, and the decrease of the inhibitory neurotransmitters vasoactive intestinal peptide and nitric oxide participate in the abnormal secretion and absorption of the GI tract [27].

In humans, MOR is expressed in both the myenteric and submucosal plexuses throughout the small and large intestine, and DOR and KOR are distributed in excitatory and inhibitory motor neurons in the human colon [28]. MOR is more distributed in the submucosal plexus than in the myenteric plexus. The activation of MOR can delay gastric emptying, increase gastrointestinal transit time, and suppress the secretion of water and electrolytes in the intestine. KOR appears more in the myenteric plexus. Most enteric neurons coexpress MOR and DOR receptors [29]. MOR and DOR are the primary opioid receptors for the regulation of enteric neurons. MOR and DOR are both distributed in the submucosal plexus and myenteric plexus, and the activation of MOR and DOR suppresses the excitation of enteric neurons by hyperpolarizing them, delays gastric emptying, increases the time of gastrointestinal transit, and suppresses the secretion of water and electrolytes in the intestine. The activation of KOR also inhibits the ENS contractile response, but its inhibition of the GI tract is weaker than that of MOR and DOR [30, 31].

\section{Methods}

To investigate the effect of opioids on the GI function in the ICU, we searched PubMed and Embase from inception until September 2021. We used the keywords "ICU OR intensive care OR critically ill OR critical care", "gastrointestinal OR gut OR constipation OR abdominal OR gastr" OR bowel", "opioid" OR opiate" and "clinical stud"." Clinical studies associated with opioids and GI function in ICU adult patients were included. Paper in a 


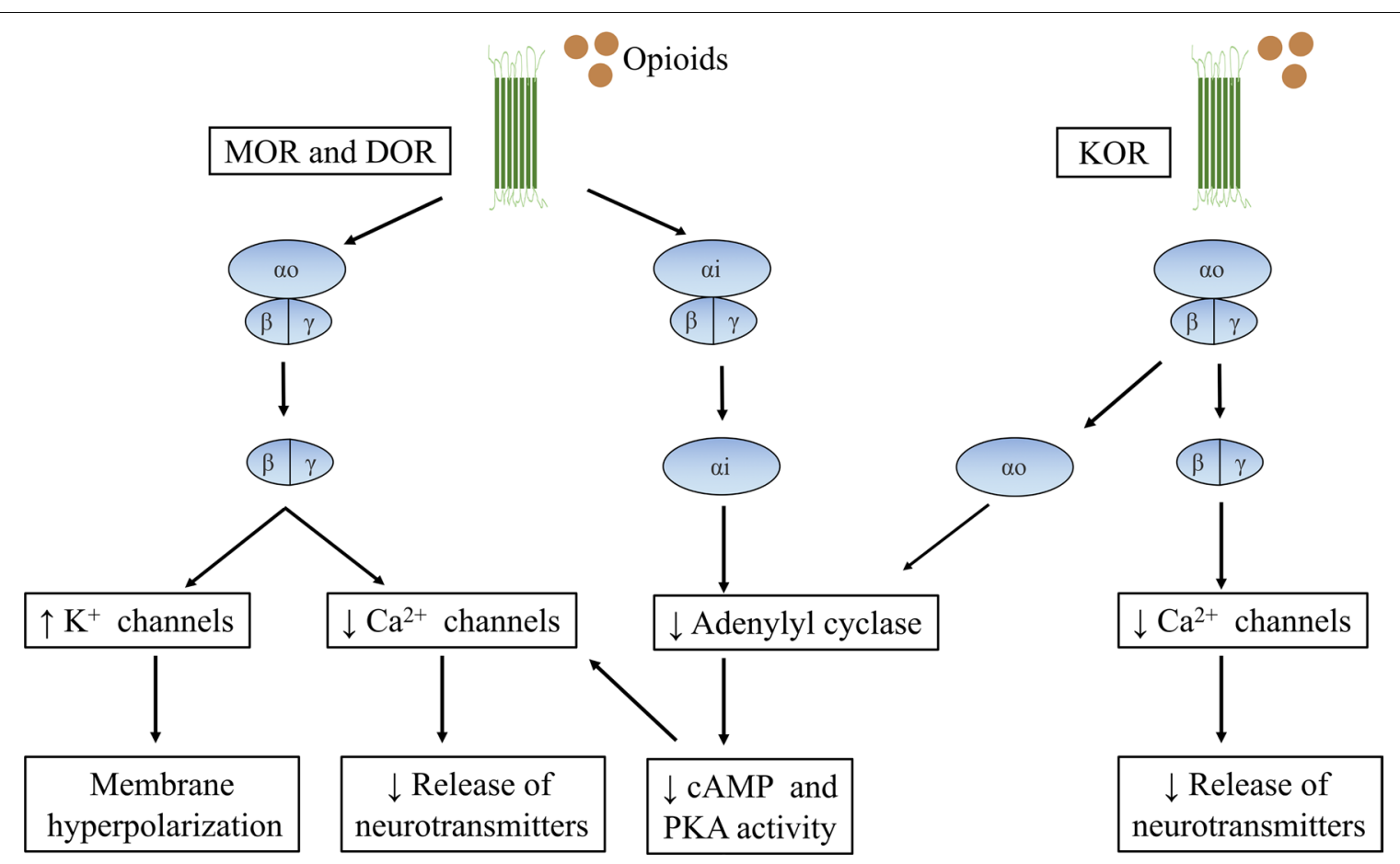

Fig. 2 Activation of opioid receptors in the enteric nervous system. MOR mu opioid receptor, DOR delta opioid receptor, KOR kappa opioid receptor, cAMP cyclic adenosine monophosphate, PKA protein kinase $\mathrm{A}$

language other than English and pediatric studies were excluded.

\section{Results}

The initial search yielded 1155, with 520 in PubMed and 635 in Embase. After screening by title and abstract, 1103 were removed for duplication articles, reviews, pediatric studies, and articles that did not report the relationship between opioids and GI function in critically ill patients. 52 papers were screened by reading full articles. In the final, 26 articles reported the effect of opioids on the GI function in ICU patients, and one clinical study was added after reference search. The detailed information about the studies is listed in Table1, 2, and 4.

\section{Upper GI dysmotility}

Upper GI dysfunction occurs frequently in ICU patients [32]. Upper GI disorders include delayed gastric emptying, increased gastroesophageal reflux and abnormal duodenal contractions. All of these disorders increase the risk of nosocomial pneumonia [33]. A retrospective study describing the gut function of current ICU patients indicated that gastric emptying was abnormal, and most enterally fed patients exhibited large gastric aspirates [34]. Delayed gastric emptying is one manifestation of feed intolerance and can result in inadequate nutrition. Sedation with the combination of midazolam and fentanyl was an independent factor for increased gastric aspirate volume and upper digestive intolerance for enteral nutrition [35]. Opioids inhibit gastric emptying in a dose-dependent pattern [32]. A prospective cohort study measured the variables associated with impaired gastric emptying using the acetaminophen absorption model [32]. Before acetaminophen treatment, 24 patients were infused with morphine or a morphine equivalent; patients treated with opioids took longer to reach maximum concentration of acetaminophen, and a high dose of opioids accompanied significant impairment of gastric emptying. A study analysed the effect of opioids on GI motility in patients on mechanical ventilation [36]. Compared with nine healthy volunteers, the migrating motor complex (MMC) of seven mechanically ventilated patients treated with morphine was significantly shortened. Meanwhile, the gastric retention of the patients was more than $20 \%$ due to the abnormal motility pattern of the MMC. When morphine was stopped, the motility pattern of the stomach could convert to a normal pattern, and mean gastric retention was decreased [36]. Nguyen et al. evaluated the effect of morphine and midazolam (M\&M) or propofol on gastric emptying by gastric scintigraphy [37]. The half-life of gastric emptying in patients receiving $M \& M$ was 153 min, longer than the half-life of $58 \mathrm{~min}$ in the control group receiving propofol, and M\&M-treated patients had higher proximal meal 


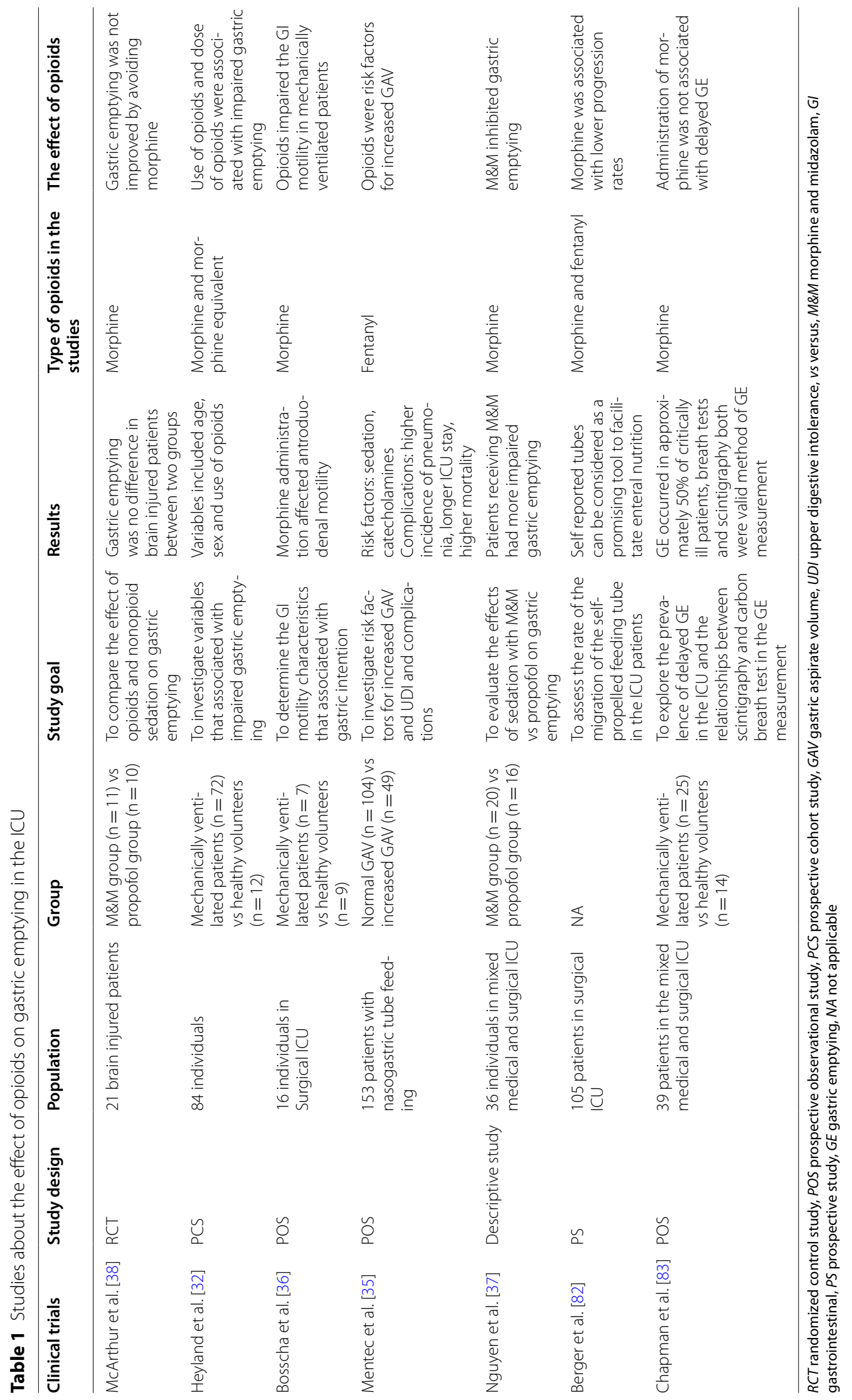




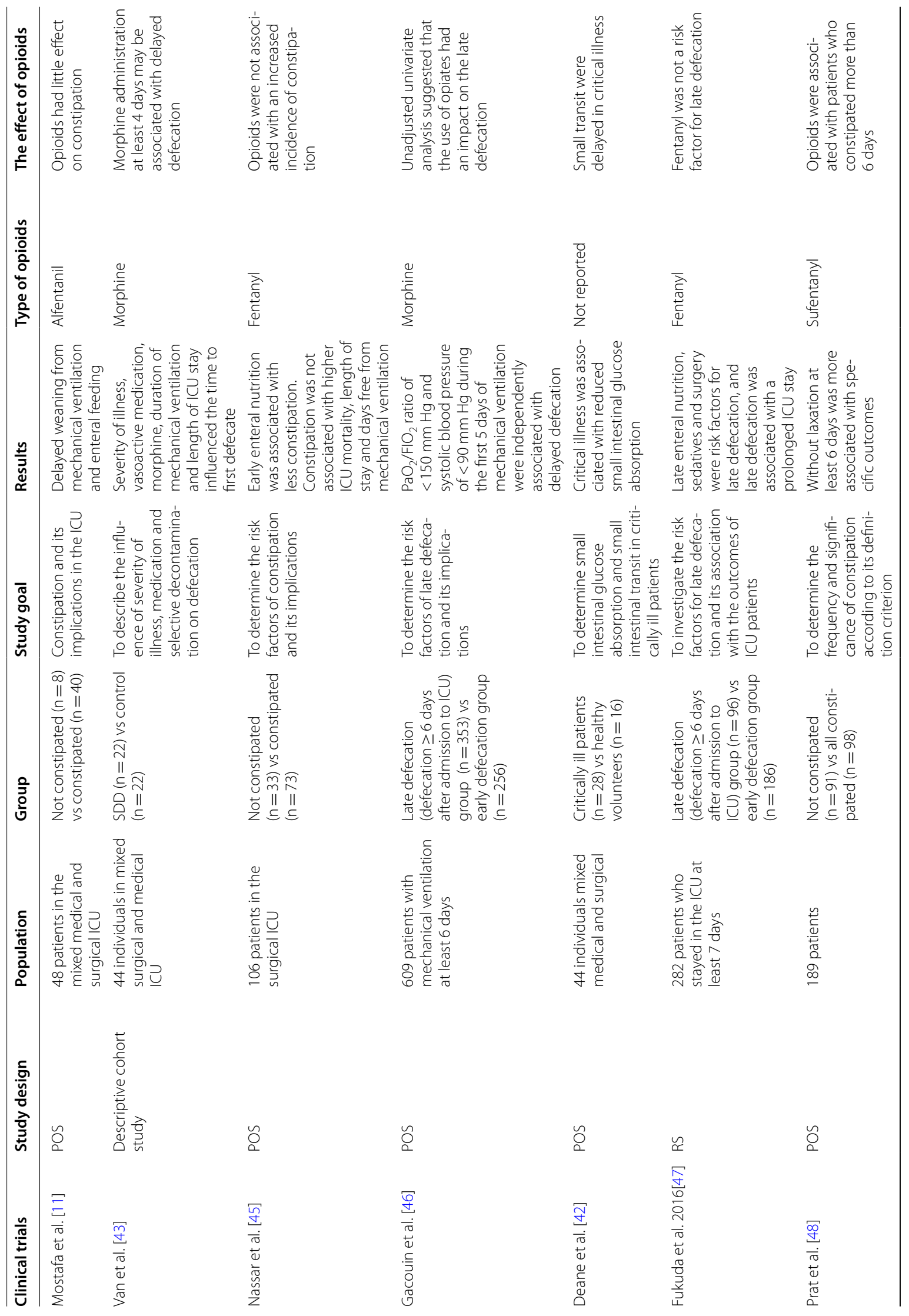




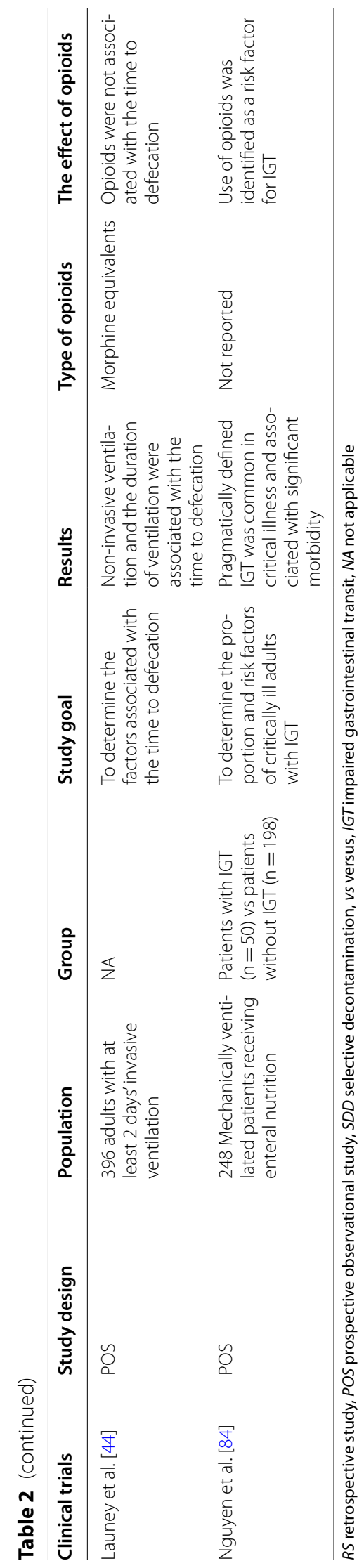


retention because morphine inhibited gastric emptying by increasing retrograde duodenal contractions and pyloric tone.

Only a prospective randomized study compared the effect of morphine plus midazolam and propofol sedation on 21 ventilated patients with brain injuries by the paracetamol absorption mode [38]. However, there was no difference between the two groups because the study had a small sample size to detect a difference in gastric emptying, and gastric emptying was influenced by other factors that were more important than opioids [38]. Nguyen et al. analysed six cohort studies with 132 patients to explore gastric emptying in critically ill patients. The authors reported that opioid medication had no association with delayed gastric emptying. Even though the sample size of this study was larger than the others, it had limitations similar to retrospective studies [39]. Table 1 lists clinical studies about the effect of opioids on gastric emptying in the ICU. The results regarding opioids in gastric emptying were inconsistent, and only a randomized study and a pooled analysis suggested that opioids had little effect on gastric emptying. Other studies demonstrated that opioids increased the risk for impaired gastric emptying, but these studies were mostly observational studies with relatively low-quality evidence, and none of these studies excluded the effects of sedatives, such as propofol and midazolam. Sedatives also had an inhibitory effect on GI function. The GI function of critically ill patients is vulnerable and can be affected by many other factors. The exact role of opioid administration in delayed gastric emptying is unclear in the ICU setting due to sparse data.

\section{Lower GI dysmotility}

The inhibition by opioids in lower GI transit has been described in detail [21, 40,41]. However, studies of their effects on the small intestines of critically ill patients are rare. A prospective study demonstrated that opioids inhibited the small intestinal transit of ICU patients [42]. Constipation is a common presentation of lower gastrointestinal dysmotility in ICU patients. However, the definition of constipation in critically ill patients is not agreed on [43]. The association between the clinical outcomes of ICU patients and the time of defecation is controversial. Some studies have suggested that constipation was associated with increased mortality, but some studies demonstrated that constipation was related to a more prolonged ICU stay but not mortality [44-46]. Therefore, it should be recognized that it is not whether defecation impacts mortality but failure to defecate after medication [45].

Opioids are an important factor in the development of constipation [34]. Constipation occurred in 16-83\% of patients in the ICU and was associated with delayed enteral feeding, bacterial translocation, and delayed weaning from mechanical ventilation [11]. However, there is no direct evidence that opioid administration is independently associated with time to defecate in critically ill patients [44]. Some studies only indirectly demonstrated that opioid administration had little effect on constipation in the ICU setting (Table 2).

In a prospective study of motility of the lower GI tract in ICU patients, the authors found similar use of alfentanil in patients with and without constipation, which suggested that alfentanil had little effect on constipation. The authors also suggested that constipation was not associated with mortality in this study [11]. The administration of fentanyl in ICU patients was also not associated with an increased risk of constipation [45, 47]. However, a descriptive cohort study demonstrated that prolonged treatment with morphine was a risk factor for late defecation in critically ill patients, but morphine administration was significantly different between early defecation and late defecation on Days 5, 6 and 7 in the ICU, but not in the first 4 days [43]. In this study, late defecation was defined as defecation six days after admission to the ICU [43]. Dominique et al. also proposed that the use of sufentanyl and midazolam were risk factors for patients' constipation between 3 and 6 days [48]. All these studies did not directly compare the effect of opioid administration on constipation, and different opioid drugs and the duration of opioid administration may have different effects on GI function. The effect of opioids on GI function depends on detailed opioid administration and infusion time. The long-term use of morphine in patients might reflect a more critical illness and multiple therapies; therefore, it is difficult to distinguish the effect of morphine or the illness itself and other factors on GI dysfunction [43]. GI motility is sensitive to various stresses and critical illnesses (Fig. 3), and critical illness itself can also cause GI dysmotility by diminished numbers of interstitial cells of Cajal in the GI tract [49]. Therefore, whether opioid administration delayed defecation in ICU patients is unclear.

\section{Potential increased infection risk by opioids}

The microbiome is one of the crucial parts of the GI barrier. However, the composition and diversity of the microbial community are severely impaired in critically ill patients and can further exacerbate illness progression [50]. Opioids are increasingly considered to cause immunosuppression, compromise the GI barrier, alter microbiome function and increase infection risk [51]. Disturbances in microbiological composition and diversity were associated with the mortality of critically ill patients [52]. Opioids can expedite the invasion of the 
Pharmacologic therapy

- Vasopressors

- Antibiotics

- Sedatives and Opioids

- Stress ulcer prophylaxis

- Neuromuscular blocking agents

\section{Risk of $\mathrm{GI}$} Dysfunction

Nonpharmacologic therapy

- Immobility

- Major surgery

- Mechanical ventilation

- Massive fluid resuscitation
Critical illness

- Shock

- Trauma

- Liver failure

- Serious infection

- Acute kidney injury

- Coagulation dysfunction

Acid-base and electrolyte disorders

- Hypokalemia

- High glucose

- High lactic acid

- Imbalances in $\mathrm{pH}$

Fig. 3 Risks of Gl dysfunction in the ICU

pathogen to the host and increase the mortality of septic mice [53]. Pathogen clearance is impaired in septic animals treated with morphine, resulting in a higher bacterial load in different organs [53]. Opioids can also enhance susceptibility to Pseudomonas aeruginosa, Enterococcus faecalis, and Listeria monocytogenes [53-57]. Both morphine and methadone administration can lead to high mortality in septic mice, and morphine contributes to bacterial dissemination and overproduction of the proinflammatory cytokine interleukin-17A (IL-17A) through activation of TLR2 and disrupts the IL-23/ IL-17-mediated defence system of innate and acquired immunity [53, 58]. The overexpression of IL-17A plus morphine treatment can increase GI permeability, impair gut epithelial barrier function and lead to higher bacterial load and higher mortality [53]. Morphine treatment increases Citrobacter rodentium virulence and dissemination into the mesenteric lymph nodes, spleen, liver and blood, promotes bacterial adherence to the small intestine, and disrupts the integrity of the epithelial barrier and the IL-17A immune response. [52]. Citrobacter rodentium alone cannot contribute to severe GI damage in the early phase of infection [52]. Morphine-induced changes in the GI microbiome occur in a receptordependent manner and can be inhibited by opioid antagonists $[51,55]$. The impact of morphine administration on pathogen virulence has been well studied, but the effect of other opioids on virulence is unclear [59].

Some clinical studies have suggested that opioids can destroy the immune response and increase susceptibility to infection [60]. Several cohort studies have demonstrated that opioid treatment leads to taxonomic changes and changes in richness and diversity in the gut microbiota [61-63]. A retrospective cohort study also found that patients using long-acting opioids with previously reported immunosuppression had the greatest risk of serious infection compared to patients without previously reported immunosuppression [60]. Many critically ill patients are immunocompromised, and it is essential to carefully select opioid drugs to avoid promoting further immunosuppression [64]. The serum level of morphine was found to be dramatically increased in patients with severe sepsis or septic shock [65]. A retrospective survey illustrated the impact of opioid analgesics on postburn infection complications. High opioid intake was associated with infectious complications in patients with mild to moderate $(<26 \%$ total body surface area) injuries [66]. However, studies about potential infection risks of opioids are rare in the ICU setting: more evidence is needed for critically ill patients.

\section{Treatment of GI dysmotility with opioid antagonists}

Although patients are traditionally given an osmotic laxative or a stimulant laxative to treat constipation, constipation still causes serious GI complications such as bowel perforation and even death [67]. Opioid antagonists are often a last-line medication for patients with opioidinduced constipation (OIC) in the ICU [67]. Opioid antagonists can be divided into peripheral acting or both peripheral-mediated and central-mediated antagonists 


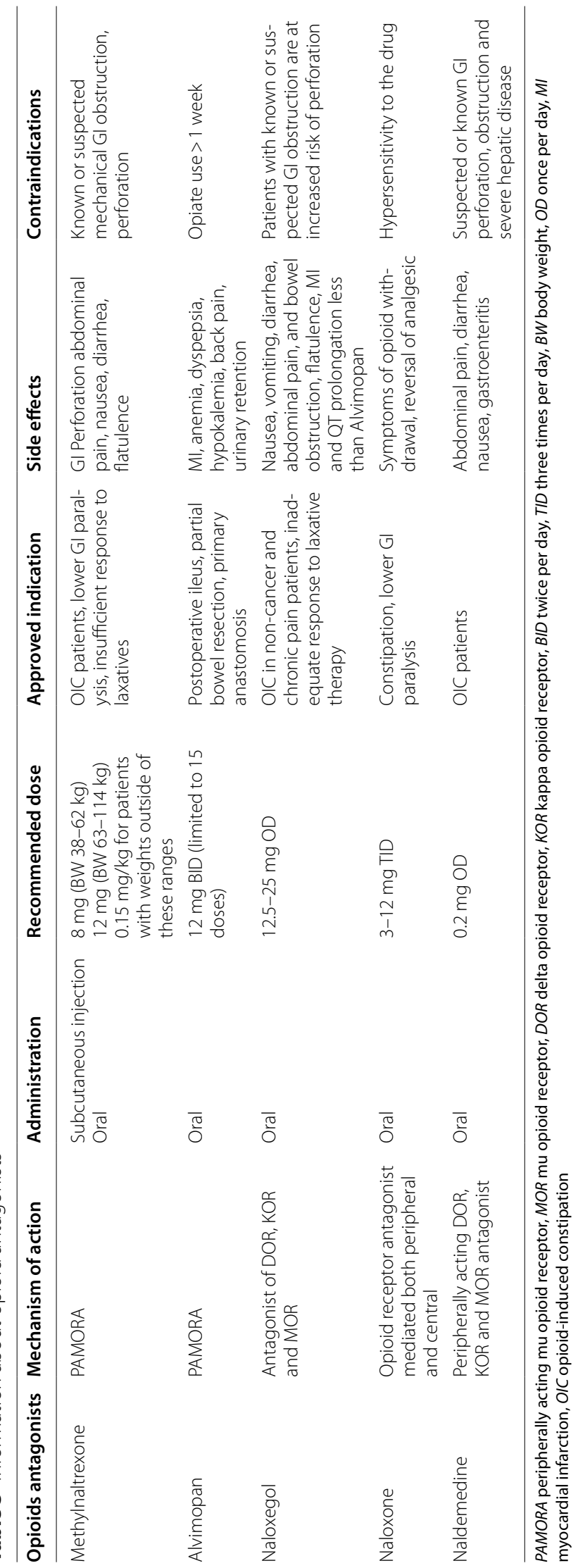




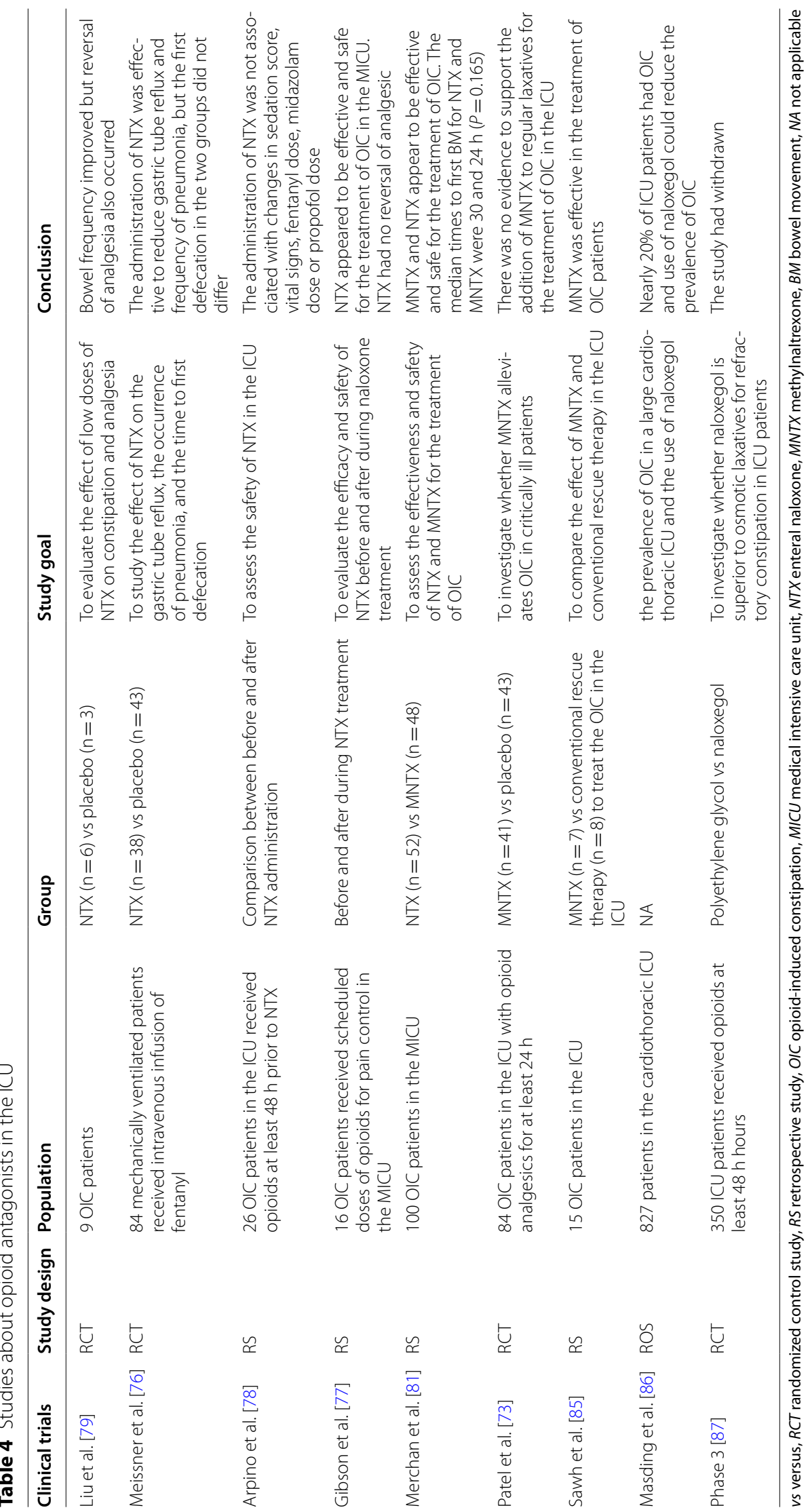


(Table 3). Peripherally acting mu opioid receptor antagonists (PAMORAs) have a limited ability to breach the blood-brain barrier, hence having no effect on the analgesic benefits, and have a blunt effect of opioids in the GI system [68]. Centrally mediated opioid antagonists can ameliorate GI hypomotility but may cross the bloodbrain barrier and reverse analgesia [69].

\section{Methylnaltrexone}

Methylnaltrexone is a methylated form of naltrexone that can be administered as an oral formulation and a subcutaneous injection [70]. Methylnaltrexone has been demonstrated to be safe and beneficial for the treatment of OIC in both preclinical studies and clinical studies. In mice, methylnaltrexone can effectively reverse morphineinduced reductions in the inhibition of bowel contraction in a concentration-related manner when administered 15 min before morphine and without compromising analgesia [71]. In guinea pigs, methylnaltrexone also reversed GI inhibition by chronic morphine treatment, but methylnaltrexone had no effect on GI transit without opioid stimulation [72]. In humans, methylnaltrexone was first approved by the Food and Drug Administration (FDA) for the treatment of OIC in patients with advanced illness when the response to laxative therapy was insufficient [68]. However, studies on the safety of methylnaltrexone in the ICU is rare. The methylnaltrexone for the Treatment of Opioid Induced Constipation and Gastrointestinal Stasis in Intensive Care Patients (MOTION) trial was a multicentre, double-blind, randomized placebocontrolled trial. This study aimed to investigate whether methylnaltrexone alleviated OIC in critical care patients [73]. The MOTION trial enrolled 84 patients; 41 patients in the methylnaltrexone group and 43 in the placebo group were finally analysed. However, this study found no significant difference in time to rescue-free laxation (Hazard ratio 1.42 , 95\% CI $0.82-2.46, p=0.22$ ) or in gastric residual volume between the groups.

\section{Naloxone}

Naloxone is mu-opioid antagonist approved by FDA for the reversal of respiratory depression caused by opioid overdose. Naloxone alleviated the inhibitory effects of the central and peripheral opioid systems on the whole and upper GI transit in mice [74]. However, naloxone can cause centrally mediated jumping behaviour in animals [75]. Several clinical studies have investigated the effect of naloxone in the ICU setting. A prospective, randomized, double-blinded study evaluated the effect of enteral naloxone on the amount of gastric tube reflux and the time of first defecation in mechanically ventilated patients who received fentanyl analgesia [76]. This study provided evidence that the administration of enteral opioid antagonists in ventilated patients reduced gastric tube reflux, but there was no difference in the time of first defecation. Naloxone did not contribute to changes in the sedation score, vital signs, fentanyl dose, midazolam dose or propofol dose in the ICU setting and appeared to be safe for OIC treatment in the medical intensive care unit (MICU) [77, 78]. However, a double-blind, randomized, placebo-controlled study suggested that nine patients who received oral naloxone had enhanced bowel frequency, and three of the nine patients had reversal of analgesia [79]. The study showed that patients treated with higher doses of opioids appeared to be more sensitive to the analgesic reversal effect of oral naloxone, and even dividing the dose could cause the reversal of analgesia $[67,79]$.

\section{Alvimopan}

Alvimopan, a PAMORA, was approved by the FDA to accelerate GI function after partial large- or small-bowel resection surgery with primary anastomosis [68]. Alvimopan can reverse the delayed GI transit resulting from intestinal manipulation without the administration of opioids before surgery and improve postoperative ileus accompanied by morphine administration in a rat model of ileus [80]. Intestinal manipulation can upregulate the endogenous opioid pathway and increase the release of endogenous opioid peptides [80]. The reversal of alvimopan for delayed GI transit may be mediated via inhibition of endogenous opioid release. There are currently no clinical studies about alvimopan use in the ICU setting.

\section{Contradicted results about the use of opioid antagonists in the ICU}

At present, the most studied opioid antagonists in the ICU are methylnaltrexone and naloxone. Studies on methylnaltrexone and naloxone in the ICU setting are insufficient, and the results of their roles in the recovery of GI motility are contradictory. Most studies have suggested that naloxone and methylnaltrexone appeared to be effective and safe in treating OIC, but two RCT studies concluded that both of the medications had little effects for OIC treatment in the ICU $[73,76]$. A possible reason for this outcome may be the study design. The RCTs matched baseline between groups, the distribution of confounding factors was also well balanced and there was a small bias compared with the retrospective study. Another reason is the number of patients. Studies with a smaller number of patients have a smaller fragility index, and several incidental events can reverse the study results. Meanwhile, a retrospective review assessed the effectiveness and safety of naloxone and subcutaneous methylnaltrexone for OIC treatment in the MICU. This single-centre study included 100 patients who received 
continuous fentanyl infusions for at least $72 \mathrm{~h}$, and the primary outcome was the time to first bowel movement. The results showed no difference in the primary outcomes, and the median times to first bowel movement for naloxone and subcutaneous methylnaltrexone were 30 and $24 \mathrm{~h}$, respectively $(P=0.165)$ [81]. It is difficult to compare studies of different opioid antagonists because of highly heterogeneous endpoints. There is no definitive conclusion about the effect of opioid antagonists on GI function in critically ill patients because of the relatively low quality of evidence and insufficient data in the ICU. Table 4 lists clinical studies associated with opioid antagonists in the ICU.

\section{Future directions and research}

GI function is strongly correlated with the clinical outcome of ICU patients. It is important to identify and avoid potential risk factor s for GI injury in clinical work. Opioids are frequently administered to treat pain and have potential risks for the impairment of GI function. Therefore, the role of opioids in GI dysfunction in critically ill patients should be clarified for precision medicine. What is the extent to which opioids affect GI function in the ICU setting, and what is the proportion of opioids in the causative factors of AGI in the ICU setting? Whether different types, doses and duration of opioid administration have different impacts on GI function remains unclear in the ICU. What is the best choice of opioids for critically ill patients with AGI and higher risks of AGI? Finally, the most commonly used GI motility drugs are laxatives, metoclopramide and erythromycin in the ICU setting. Patients who have an inadequate response to these drugs have great potential to receive operative treatment. In addition, most of these patients who received operative treatment have a poor prognosis. Therefore, it is imperative to evaluate the effectiveness and safety of other GI motility drugs in the ICU setting, such as opioid antagonists.

\section{Conclusion}

In conclusion, pain is common in the ICU; more than half of ICU patients suffer moderate to serious pain, and it is necessary to use analgesia. Opioids have a considerable role in pain management in the ICU setting, and various studies have demonstrated the inhibition of GI motility by opioids. However, the GI tract is highly vulnerable in critically ill patients, and many factors can influence GI function from the GI barrier and absorption to motility in the ICU setting. The extent to which opioids contribute to GI dysmotility is unclear in the ICU setting due to the paucity of published data. GI dysmotility is on the severe side of the spectrum and should be adequately managed. However, at present, medication for GI dysmotility is limited in the ICU setting. Therefore, it is crucial to maintain a good balance between GI function and opioid administration. In the prescription of opioid drugs, many properties need to be taken into account before medication choices are finalized.

\section{Abbreviations}

Gl: gastrointestinal; WGAP: Working Group on Abdominal Problems; AGl: acute gastrointestinal injury; ENS: enteric nervous system; MOR: mu opioid receptor; DOR: delta opioid receptor; KOR: kappa opioid receptor; MMC: migrating motor complex; M\&M: morphine and midazolam; IL-17A: interleukin-17A; OIC: opioid-induced constipation; PAMORA: peripherally acting mu opioid receptor antagonists; MOTION: the methylnaltrexone for the treatment of opioid induced constipation and gastrointestinal stasis in intensive care patients; MICU: medical intensive care unit; FDA: food and drug administration.

\section{Acknowledgements \\ None.}

\section{Authors' contributions}

Both authors had their substantial contributions to the conception or design of the work. YY drafted the work. CY and ZXJ revised it critically for important intellectual content. Both authors read and approved the final manuscript.

\section{Funding}

This work was supported by the National Natural Science Foundation of China (8187081150) and the Natural Science Foundation of Shaanxi Province (21QNPY092).

Availability of data and materials

Not applicable.

\section{Declarations}

Ethics approval and consent to participate

Not applicable.

\section{Consent for publication}

Not applicable.

\section{Competing interests}

The authors declare that they have no competing interests.

\section{Author details}

${ }^{1}$ Department of Anaesthesiology and Perioperative Medicine, Xijing Hospital, The Fourth Military Medical University, Xi'an, China. ${ }^{2}$ Department of Critical Care Medicine, Xijing Hospital, The Fourth Military Medical University, Xi'an, China.

Received: 2 August 2021 Accepted: 12 October 2021

Published online: 24 October 2021

\section{References}

1. Rombeau JL, Takala J. Summary of round table conference: gut dysfunction in critical illness. Intensive Care Med. 1997;23:476-9.

2. Reintam A, Kern H, Starkopf J. Defining gastrointestinal failure. Acta Clin Belg. 2007;62(Suppl 1):168-72. https://doi.org/10.1179/acb.2007.62.s1. 022.

3. Drewes AM, Munkholm P, Simrén M, et al. Definition, diagnosis and treatment strategies for opioid-induced bowel dysfunction-Recommendations of the Nordic Working Group. Scand J Pain. 2016;11:111-22.

4. Reintam Blaser A, Jakob SM, Starkopf J. Gastrointestinal failure in the ICU. Curr Opin Crit Care. 2016;22:128-41.

5. Reintam Blaser A, Malbrain MLNG, Starkopf J, et al. Gastrointestinal function in intensive care patients: terminology, definitions and management. 
Recommendations of the ESICM Working Group on Abdominal Problems. Intensive Care Med. 2012;38:384-94.

6. Li H, Zhang D, Wang Y, et al. Association between acute gastrointestinal injury grading system and disease severity and prognosis in critically ill patients: a multicenter, prospective, observational study in China. J Crit Care. 2016;36:24-8.

7. Ding L, Chen $\mathrm{H}-\mathrm{Y}$, Wang J-Y, et al. Severity of acute gastrointestinal injury grade is a good predictor of mortality in critically ill patients with acute pancreatitis. World J Gastroenterol. 2020:26:514-23.

8. Reintam Blaser A, Starkopf J, Malbrain MLNG. Abdominal signs and symptoms in intensive care patients. Anaesthesiol Intensive Ther. 2015:47:379-87.

9. Reintam A, Parm P, Kitus R, et al. Gastrointestinal symptoms in intensive care patients. Acta Anaesthesiol Scand. 2009;53:318-24.

10. Wilmer A, Tack J, Frans E, et al. Duodenogastroesophageal reflux and esophageal mucosal injury in mechanically ventilated patients. Gastroenterology. 1999;116:1293-9.

11. Mostafa SM, Bhandari S, Ritchie G, et al. Constipation and its implications in the critically ill patient. Br J Anaesth. 2003;91:815-9.

12. Reintam A, Parm P, Kitus R, et al. Gastrointestinal failure score in critically ill patients: a prospective observational study. Crit Care. 2008;12:R90.

13. Reintam A, Parm P, Redlich U, et al. Gastrointestinal failure in intensive care: a retrospective clinical study in three different intensive care units in Germany and Estonia. BMC Gastroenterol. 2006;6:19.

14. Pyati S, Gan TJ. Perioperative pain management. CNS Drugs. 2007;21:185-211.

15. Sigakis MJG, Bittner EA. Ten myths and misconceptions regarding pain management in the ICU. Crit Care Med. 2015;43:2468-78.

16. Donohue JM, Kennedy JN, Seymour CW, et al. Patterns of opioid administration among opioid-naive inpatients and associations with postdischarge opioid use: a cohort study. Ann Intern Med. 2019:171:81-90.

17. Richards-Belle A, Canter RR, Power GS, et al. National survey and point prevalence study of sedation practice in UK critical care. Crit Care. 2016;20:355.

18. Friedman A, Nabong L. Opioids: pharmacology, physiology, and clinical implications in pain medicine. Phys Med Rehabil Clin N Am. 2020;31:289-303.

19. Patel D, Callaway J, Vaezi M. Opioid-induced foregut dysfunction. Am J Gastroenterol. 2019;114:1716-25.

20. Akbarali HI, Dewey WL. Gastrointestinal motility, dysbiosis and opioidinduced tolerance: is there a link? Nat Rev Gastroenterol Hepatol. 2019:16:323-4

21. Rossi M, Casale G, Badiali D, et al. Opioid-induced bowel dysfunction: suggestions from a multidisciplinary expert board. Support Care Cancer. 2019;27:4083-90

22. Fruhwald $\mathrm{S}$, Holzer $\mathrm{P}$, Metzler $\mathrm{H}$. Intestinal motility disturbances in intensive care patients pathogenesis and clinical impact. Intensive Care Med. 2007;33:36-44.

23. DeHaven-Hudkins DL, DeHaven RN, Little PJ, et al. The involvement of the mu-opioid receptor in gastrointestinal pathophysiology: therapeutic opportunities for antagonism at this receptor. Pharmacol Ther. 2008;117:162-87.

24. Wood JD, Galligan JJ. Function of opioids in the enteric nervous system. Neurogastroenterol Motil. 2004;16(Suppl 2):17-28.

25. Galligan JJ, Akbarali HI. Molecular physiology of enteric opioid receptors. Am J Gastroenterol Suppl. 2014;2:17-21.

26. Sternini C, Patierno S, Selmer I-S, et al. The opioid system in the gastrointestinal tract. Neurogastroenterol Motil. 2004;16(Suppl 2):3-16.

27. Sobczak M, Sałaga M, Storr MA, et al. Physiology, signaling, and pharmacology of opioid receptors and their ligands in the gastrointestinal tract: current concepts and future perspectives. J Gastroenterol. 2014;49:24-45.

28. Galligan JJ, Sternini C. Insights into the role of opioid receptors in the Gl tract: experimental evidence and therapeutic relevance. Handb Exp Pharmacol. 2017:239:363-78.

29. Poole DP, Pelayo J-C, Scherrer G, et al. Localization and regulation of fluorescently labeled delta opioid receptor, expressed in enteric neurons of mice. Gastroenterology. 2011;141:982-991.e18.

30. Mitolo-Chieppa D, Natale L, Marasciulo FL, et al. Involvement of kappa-opioid receptors in peripheral response to nerve stimulation in kappa-opioid receptor knockout mice. Auton Autacoid Pharmacol. 2002:22:233-9.
31. Albert-Vartanian A, Boyd MR, Hall AL, et al. Will peripherally restricted kappa-opioid receptor agonists (pKORAs) relieve pain with less opioid adverse effects and abuse potential? J Clin Pharm Ther. 2016;41:371-82.

32. Heyland DK, Tougas $G$, King D, et al. Impaired gastric emptying in mechanically ventilated, critically ill patients. Intensive Care Med. 1996;22:1339-44

33. Nind G, Chen W-H, Protheroe R, et al. Mechanisms of gastroesophageal reflux in critically ill mechanically ventilated patients. Gastroenterology. 2005:128:600-6.

34. Heinonen T, Ferrie S, Ferguson C. Gut function in the intensive care unit: what is "normal"? Aust Crit Care. 2020:33:151-4.

35. Mentec $\mathrm{H}$, Dupont $\mathrm{H}$, Bocchetti $\mathrm{M}$, et al. Upper digestive intolerance during enteral nutrition in critically ill patients: frequency, risk factors, and complications. Crit Care Med. 2001;29:1955-61.

36. Bosscha K, Nieuwenhuijs VB, Vos A, et al. Gastrointestinal motility and gastric tube feeding in mechanically ventilated patients. Crit Care Med. 1998;26:1510-7.

37. Nguyen NQ, Chapman MJ, Fraser RJ, et al. The effects of sedation on gastric emptying and intra-gastric meal distribution in critical illness. Intensive Care Med. 2008:34:454-60.

38. McArthur CJ, Gin T, McLaren IM, et al. Gastric emptying following brain injury: effects of choice of sedation and intracranial pressure. Intensive Care Med. 1995;21:573-6.

39. Nguyen NQ, Ng MP, Chapman M, et al. The impact of admission diagnosis on gastric emptying in critically ill patients. Crit Care. 2007;11:R16. https:// doi.org/10.1186/cc5685.

40. Webster LR. Opioid-induced constipation. Pain Med. 2015;16(Suppl 1):16-21.

41. De Giorgio R, Zucco FM, Chiarioni G, et al. Management of opioidinduced constipation and bowel dysfunction: expert opinion of an Italian multidisciplinary panel. Adv Ther. 2021. https://doi.org/10.1007/ s12325-021-01766-y.

42. Deane AM, Summers MJ, Zaknic AV, et al. Glucose absorption and small intestinal transit in critical illness. Crit Care Med. 2011;39:1282-8.

43. van der Spoel Jl, Schultz MJ, van der Voort PHJ, et al. Influence of severity of illness, medication and selective decontamination on defecation. Intensive Care Med. 2006;32:875-80.

44. Launey Y, Painvin B, Roquilly A, et al. Factors associated with time to defecate and outcomes in critically ill patients: a prospective, multicentre, observational study. Anaesthesia. 2021;76:218-24.

45. Nassar AP, da Silva FMQ, de Cleva R. Constipation in intensive care unit: incidence and risk factors. J Crit Care. 2009;24(630):e9-12. https://doi.org/ 10.1016/j.jcrc.2009.03.007.

46. Gacouin A, Camus C, Gros A, et al. Constipation in long-term ventilated patients: associated factors and impact on intensive care unit outcomes. Crit Care Med. 2010;38:1933-8.

47. Fukuda S, Miyauchi T, Fujita M, et al. Risk factors for late defecation and its association with the outcomes of critically ill patients: a retrospective observational study. J Intensive Care. 2016;4:33.

48. Prat D, Messika J, Avenel A, et al. Constipation incidence and impact in medical critical care patients: importance of the definition criterion. Eur J Gastroenterol Hepatol. 2016;28:290-6.

49. Shimizu K, Ogura H, Matsumoto N, et al. Interstitial cells of Cajal are diminished in critically ill patients: autopsy cases. Nutrition. 2020;70:110591.

50. Alverdy JC, Krezalek MA. Collapse of the microbiome, emergence of the pathobiome, and the immunopathology of sepsis. Crit Care Med. 2017:45:337-47.

51. Banerjee S, Sindberg G, Wang F, et al. Opioid-induced gut microbial disruption and bile dysregulation leads to gut barrier compromise and sustained systemic inflammation. Mucosal Immunol. 2016;9:1418-28.

52. Wang F, Meng J, Zhang L, et al. Opioid use potentiates the virulence of hospital-acquired infection, increases systemic bacterial dissemination and exacerbates gut dysbiosis in a murine model of Citrobacter rodentium infection. Gut Microbes. 2020;11:172-90.

53. Meng J, Banerjee S, Li D, et al. Opioid exacerbation of gram-positive sepsis, induced by gut microbial modulation, is rescued by IL-17A neutralization. Sci Rep. 2015;5:10918.

54. Babrowski T, Holbrook C, Moss J, et al. Pseudomonas aeruginosa virulence expression is directly activated by morphine and is capable of causing 
lethal gut-derived sepsis in mice during chronic morphine administration. Ann Surg. 2012;255:386-93.

55. Wang $F$, Meng J, Zhang $L$, et al. Morphine induces changes in the gut microbiome and metabolome in a morphine dependence model. Sci Rep. 2018;8:3596.

56. Shakhsheer BA, Versten LA, Luo JN, et al. Morphine promotes colonization of anastomotic tissues with collagenase: producing Enterococcus faecalis and causes leak. J Gastrointest Surg. 2016;20:1744-51.

57. Asakura H, Kawamoto K, Igimi S, et al. Enhancement of mice susceptibility to infection with Listeria monocytogenes by the treatment of morphine. Microbiol Immunol. 2006;50:543-7.

58. Ma J, Wang J, Wan J, et al. Morphine disrupts interleukin-23 (IL-23)/IL17-mediated pulmonary mucosal host defense against Streptococcus pneumoniae infection. Infect Immun. 2010;78:830-7.

59. Hamilton $L A$, Behal ML. Altering routine intensive care unit practices to support commensalism. Nutr Clin Pract. 2020;35:433-41.

60. Wiese AD, Griffin MR, Schaffner W, et al. Long-acting opioid use and the risk of serious infections: a retrospective cohort study. Clin Infect Dis. 2019;68:1862-9.

61. Vincent C, Miller MA, Edens TJ, et al. Bloom and bust: intestinal microbiota dynamics in response to hospital exposures and Clostridium difficile colonization or infection. Microbiome. 2016:4:12.

62. Acharya C, Betrapally NS, Gillevet PM, et al. Chronic opioid use is associated with altered gut microbiota and predicts readmissions in patients with cirrhosis. Aliment Pharmacol Ther. 2017:45:319-31.

63. Zhernakova A, Kurilshikov A, Bonder MJ, et al. Population-based metagenomics analysis reveals markers for gut microbiome composition and diversity. Science. 2016;352:565-9.

64. Budd K. Pain management: is opioid immunosuppression a clinical problem? Biomed Pharmacother. 2006;60:310-7.

65. Glattard E, Welters ID, Lavaux T, et al. Endogenous morphine levels are increased in sepsis: a partial implication of neutrophils. PLOS ONE. 2010;5:e8791.

66. Schwacha MG, McGwin G, Hutchinson CB, et al. The contribution of opiate analgesics to the development of infectious complications in burn patients. Am J Surg. 2006;192:82-6.

67. Saini HS, Alvi Z, Singh B, et al. Methylnaltrexone and naloxone for opioidinduced constipation in the critical care setting. Cureus. 2020;12:e6829.

68. Schwenk ES, Grant AE, Torjman MC, et al. The efficacy of peripheral opioid antagonists in opioid-induced constipation and postoperative ileus: a systematic review of the literature. Reg Anesth Pain Med. 2017;42:767-77.

69. Reintam Blaser A, Preiser J-C, Fruhwald S, et al. Gastrointestinal dysfunction in the critically ill: a systematic scoping review and research agenda proposed by the Section of Metabolism, Endocrinology and Nutrition of the European Society of Intensive Care Medicine. Crit Care. 2020;24:224.

70. Pergolizzi JV Jr, Christo PJ, LeQuang JA, et al. The use of peripheral $\mu$-opioid receptor antagonists (PAMORA) in the management of opioidinduced constipation: an update on their efficacy and safety. DDDT. 2020;14:1009-25.

71. Yuan CS, Foss JF, Moss J. Effects of methylnaltrexone on morphineinduced inhibition of contraction in isolated guinea-pig ileum and human intestine. Eur J Pharmacol. 1995;276:107-11.

72. Anselmi L, Huynh J, Vegezzi G, et al. Effects of methylnaltrexone on guinea pig gastrointestinal motility. Naunyn Schmiedebergs Arch Pharmacol. 2013;386:279-86.
73. Patel PB, Brett SJ, O'Callaghan D, et al. Methylnaltrexone for the treatment of opioid-induced constipation and gastrointestinal stasis in intensive care patients. Results from the MOTION trial. Intensive Care Med. 2020;46:747-55.

74. Wasilewski A, Lesniak A, Bujalska-Zadrozny M, et al. The effect of opioid agonists and antagonists on gastrointestinal motility in mice selected for high and low swim stress-induced analgesia. Neurogastroenterol Motil. 2016;28:175-85.

75. Greenwood-Van Meerveld B, Gardner CJ, Little PJ, et al. Preclinical studies of opioids and opioid antagonists on gastrointestinal function. Neurogastroenterol Motil. 2004;16(Suppl 2):46-53.

76. Meissner W, Dohrn B, Reinhart K. Enteral naloxone reduces gastric tube reflux and frequency of pneumonia in critical care patients during opioid analgesia. Crit Care Med. 2003;31:776-80.

77. Gibson CM, Pass SE. Enteral naloxone for the treatment of opioid-induced constipation in the medical intensive care unit. J Crit Care. 2014;29:803-7.

78. Arpino PA, Thompson BT. Safety of enteral naloxone for the reversal of opiate-induced constipation in the intensive care unit. J Clin Pharm Ther. 2009;34:171-5

79. Liu M, Wittbrodt E. Low-dose oral naloxone reverses opioid-induced constipation and analgesia. J Pain Symptom Manag. 2002;23:48-53.

80. Fukuda H, Suenaga K, Tsuchida D, et al. The selective mu opioid receptor antagonist, alvimopan, improves delayed $\mathrm{Gl}$ transit of postoperative ileus in rats. Brain Res. 2006;1 102:63-70.

81. Merchan C, Altshuler D, Papadopoulos J. Methylnaltrexone versus naloxone for opioid-induced constipation in the medical intensive care unit. Ann Pharmacother. 2017:51:203-8.

82. Berger MM, Bollmann MD, Revelly JP, et al. Progression rate of selfpropelled feeding tubes in critically ill patients. Intensive Care Med. 2002;28:1768-74.

83. Chapman MJ, Besanko LK, Burgstad CM, et al. Gastric emptying of a liquid nutrient meal in the critically ill: relationship between scintigraphic and carbon breath test measurement. Gut. 2011;60:1336-43.

84. Nguyen T, Frenette A-J, Johanson C, et al. Impaired gastrointestinal transit and its associated morbidity in the intensive care unit. J Crit Care. 2013;28(537):e11-7.

85. Sawh SB, Selvaraj IP, Danga A, et al. Use of methylnaltrexone for the treatment of opioid-induced constipation in critical care patients. Mayo Clin Proc. 2012;87:255-9.

86. Masding A, Kaul S. Opioid-induced constipation in intensive care-how big is the problem? J Intensive Care Soc. 2019;20:6-7. https://doi.org/10. 1007/s00134-002-1544-7.

87. Massachusetts General Hospital. The effect of naloxegol on refractory constipation in the intensive care unit (narc-ICU). In: clinicaltrials.gov [Internet]. Bethesda (MD): National Library of Medicine (US); 2000. Available from: https://clinicaltrials.gov/ct2/show/NCT02705378?

\section{Publisher's Note}

Springer Nature remains neutral with regard to jurisdictional claims in published maps and institutional affiliations.

Ready to submit your research? Choose BMC and benefit from

- fast, convenient online submission

- thorough peer review by experienced researchers in your field

- rapid publication on acceptance

- support for research data, including large and complex data types

- gold Open Access which fosters wider collaboration and increased citations

- maximum visibility for your research: over $100 \mathrm{M}$ website views per year

At BMC, research is always in progress.

Learn more biomedcentral.com/submissions 